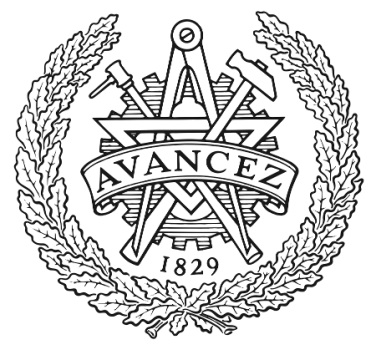

CHALMERS

UNIVERSITY OF TECHNOLOGY

\title{
Facing the New Technology Landscape in the Maritime Domain: Knowledge Mobilisation, Networks and Management in Human-Machine
}

Downloaded from: https://research.chalmers.se, 2023-04-26 11:42 UTC

Citation for the original published paper (version of record):

Man, Y., Lundh, M., MacKinnon, S. (2019). Facing the New Technology Landscape in the Maritime Domain: Knowledge Mobilisation, Networks and Management in Human-Machine Collaboration. Advances in Intelligent Systems and Computing, 786: 231-242. http://dx.doi.org/10.1007/978-3-319-93885-1_21

N.B. When citing this work, cite the original published paper. 


\title{
Facing the New Technology Landscape in the Maritime Domain: Knowledge Mobilisation, Networks and Management in Human-Machine Collaboration
}

\author{
Yemao Man ${ }^{1}$, Monica Lundh ${ }^{1}$, Scott N. MacKinnon ${ }^{1}$ \\ ${ }^{1}$ Department of Mechanics and Maritime Sciences, Chalmers University of Technology, \\ 41296 Gothenburg, Sweden \\ \{yemao.man, monica.lundh, scottm\}@chalmers.se
}

\begin{abstract}
Rapid development in artificial intelligence and big data analytic applications have had a significant impact on knowledge mobilisation across industries including the shipping domain. This paper uses the practice of energy efficiency onboard ships as a case study to discuss how knowledge mobilisation should address this context change and uncovers how existing knowledge networks in the shipping industry would evolve in this emerging data-driven ecology. From a systems perspective, it suggests hallmarks associated with the knowledge mobilisation processes in the new technology landscape. This paper shapes a discussion intended to derive design and management implications of the system infrastructure contributing to a safe, efficient and sustainable shipping business model and provide insights on knowledge adaption in the emerging human-machine collaboration context.
\end{abstract}

Keywords: Knowledge Mobilisation - Knowledge Networks · Automation · Human-Machine Collaboration · Management

\section{Introduction}

There have been many significant technological advancements since the $20^{\text {th }}$ century that are constantly shaping our human society [1-3]. One example to show the reciprocal relationship between human and automation is the rise in importance of industrial robots in the field of manufacturing. In the past, the robots were mainly designed as highly specialized machines to accomplish routine tasks using repetitive actions within a confined space to increase manufacturing efficiency. Their choreographed performance is a result of expensive and complicated programming. Human knowledge and experience is hardcoded into these robots in terms of strong demand in the precision of time and positioning. Although there were many workers being made redundant within the manufacturing sector, robots still could not undertake adaptive, dexterousness and non-routine tasks. That was yesterday, literally and figuratively, as automation is allowing robots to "learn" to become more capable and versatile. Modern robots have become more functional and practical. Industrial Perception, Inc. is a company in Silicon Valley that develops touch- and vision-based sensing solutions to enable robots to undertake more complicated industrial tasks.

(C) Springer International Publishing AG, part of Springer Nature 2019

N. Stanton (Ed.): AHFE 2018, AISC 786, pp. 231-242, 2019.

https://doi.org/10.1007/978-3-319-93885-1_21 
Rethink Robotics is another well-known start-up based in Boston, Massachusetts that produces collaborative robots, such as the 3 -foot tall two-armed Baxter robot with an animated face. The Baxter robots are equipped with enhanced robotic capabilities in visual perception, adaptive behaviour and knowledge acquisition and show humanlevel potentials to interact with the environment [1]. Their performances are a result of a collaborative form of training by human workers instead of programming, changing the way the humans "infuse" knowledge into machines. In some cases, a machine's knowledge is not even reinforced by the human. AlphaGo is the first program that employed deep neural networks to defeat a world champion in the game of Go (an ancient Chinese board game with extreme computational complexity [4] that has far more possible legal positions than the estimated number of atoms in the observable world). AlphaGo becomes its own teacher by relying on reinforcement learning without human data, guidance or domain knowledge beyond game rules [5]. Today machines are designed to attempt to take accountability and perform at more than the skill- or rule-based levels, i.e. invading the human's long-standing territory of the knowledge-based level described in Rasmussen's Skill-Rules-Knowledge Behaviour Model [6] .

The technological innovation of artificial intelligence, business intelligence and big data analytics applications have certainly gone beyond the board game or the manufacturing sector. The maritime domain, which is one the most traditional and conservative of industries, is currently in the transition phase driven by this fastchanging technology landscape. Many digitalized products, applications and services have been introduced into the shipping industry to provide maritime users a plethora of platforms and decision support tools to access information and maintain system control [7], such as energy-efficient fuel monitoring systems [8], unmanned cargo handling systems in the world's largest automated terminal [9], autonomous unmanned ships [10-12], etc. Intelligent systems are constantly shifting the human operators' role. Traditional Human Machine Interaction is transforming to Human Machine Cooperation [13] with the operator's role progressively shifting from a controller to a mission manager or supervisor of the system [14]. At the same time, technology keeps expanding its territory into a value-creating knowledge level with ubiquitous, mostly heterogeneous and distributed data to support and assist humans. The reciprocal relationship between human and advanced technology is shifting from master-slave servomechanisms towards collaboration and coordination [15]. This rapid technological advance inevitably changes the context in which humans conventionally learn knowledge that influences work, such as how humans discover new knowledge and operate with machines to be more adaptive in those unanticipated events. While all the technical advancements are shaping a new technology landscape, some crucial questions were given much less attention, i.e. how the process of creating, sharing and managing knowledge as well as the best use of knowledge would be impacted, and how this is pertinent to design issues.

Various maritime stakeholders are likely to be influenced in the context of maritime energy efficiency (EE), such as the ship crews, management groups and designers of intellectual navigational/fuel-optimization systems. Knowledge and skills are likely the most essential factors in the ship's crew' energy optimization performance [16]. Current managerial practices do not necessarily provide sufficient support for learning and innovation within organizations [8, 17]. As automation is 
getting more functional and complicated while human operators remain the ultimate decision makers in the system, the necessity of employing appropriate design to support learning and educational purposes is becoming more important. Understanding of technology's role in knowledge mobilisation is at the nexus of practitioners' performance, organizational knowledge management and a heuristic perspective in design, yet it remains to be a prominent challenge [18]. Most previous research on learning and knowledge management focused on the social-cultural processes during which the knowledge was transferred between individuals to form various knowledge networks or the prerequisites for knowledge transfer regardless of the process used (i.e. knowledge transfer capacities) [19-23]. Confronted with the most radical context change driven by artificial intelligence, big data and the associated complexity, the impact on the development of knowledge networks and representations for effective knowledge transfer have not been sufficiently addressed.

This paper uses the practice of energy efficiency (optimization) onboard ships as a case study to discuss how the process of creating, sharing and managing knowledge should address this context change. The aim is to shed light on design strategies for learning, decision-making support systems to facilitate knowledge transfer and management within the shipping industry in the landscape of Human-Machine Collaboration.

\section{Case Study}

In recent years, there have been increasing concerns about ships' EE mainly due to economic (e.g. profitability in the shipping companies) and environmental factors (e.g. reduce greenhouse gas emission) [16]. The operational performance of ship's crews can significantly and directly influence the fuel consumption $[8,17]$, such as how the navigators safely and efficiently conduct ship-handling and how the engineers can maintain the ship's power and propulsion systems under different circumstances.

Viktorelius and Lundh [8] did a study on a modern ferry vessel to investigate the gaps pertinent to EE. The authors visited the same ship multiple times to understand the ship crews' EE practices and their deployment of EE monitoring systems. The shipping company introduced a fuel consumption monitoring system called ETA-pilot to assist the navigators to regulate the speed automatically, as speed is directly related to fuel consumption [24]. The voyage was divided into multiple legs so the ETA-pilot dynamically proposed an optimal speed for each leg based on multiple factors (e.g. ship trim/draft, depth of the water, weather information, distance to the destination and estimated time of arrival, etc.). The speed can also be automatically adjusted as the navigators may deviate the course or manually change the speed for collision avoidance purposes. The fuel consumption ( $\mathrm{kg}$ per nautical miles) was displayed as a dynamic curve along with other output parameters in a complex chart in the bottom of the user interface to provide the navigators decision support for any potential navigational correction (see Fig. 1). 


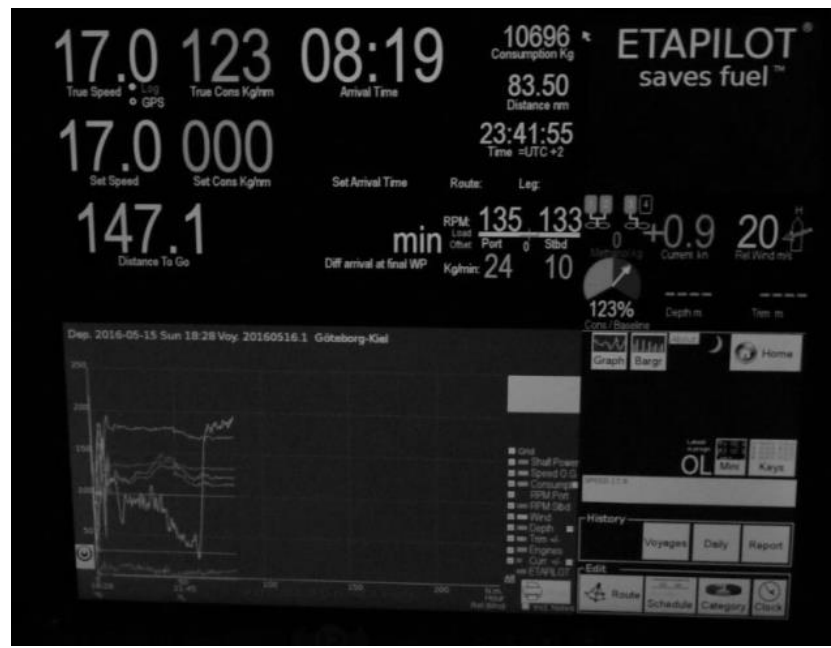

Fig. 1. The true speed (17 knots/hour) and the consumption (123 kg/nautical mile) is presented left top in the user interface of the ETA-pilot.

Although the ETA-pilot seemed to display a plethora of useful data, it was discovered that the tool failed to facilitate the crews' understanding of the impact of their actions on EE [8]. For example, the ship's crew considered it difficult to learn something out of the displayed numbers as nearly all the displayed information could hardly be integrated into the crews' practices for optimal EE performance. Rather, they relied heavily on those traditional navigational instruments and their own navigational experience to manoeuvre the ship, thus leaving the majority of the information provided by the tool un-used. Once a journey was finished, the tool would become useless for both the ship's crew and the management group onshore, though a considerable amount of data pertinent to ship performance had been collected, plotted and sent to the shipping company via the ETA-pilot. There were no evaluating activities. Learning based on reviewing historical EE performance was extremely difficult, but desired, for the ship's crew due to the lack of analytical function of the system [8].

Knowledge development of the ship's crew plays a central role in their EE performance [25]. Different navigators have different understandings and knowledge of the tool, leading to different ways of using and corresponding EE performance. Some even claimed that by disconnecting ETA-pilot, navigating manually could contribute to improved fuel savings [8]. Furthermore, current social-cultural constrains onboard and organizational structures did not necessarily facilitate the practitioners' learning. In today's prevalent top-down management approach in the shipping domain [25], the practitioners were too far down to be included in the organizational decision making process [17]. With poor analytical support from the collected data, the management could hardly understand the real problems in the field and make appropriate managerial adaptations. Most likely the explicit managerial support about knowledge transfer was in a formal and salient professional manner that only benefited an individual, e.g. 'crew members had been sent to a one day course for how to use the fuel management system' [8]. Although the engineers might have 
many ideas pertinent to EE inspired by the communities of practice [22], they seldom spoke of it on the bridge due to the social/practice boundaries between the engine and bridge department $[8,26,27]$.

\section{Discussion}

\subsection{Data-Driven Systems}

Confronted with the aforementioned issues of the ETA-Pilot tool, gaps between the ship and shore, and deck and engine room personnel, there is potentially an opportunity for the intelligent systems to actually support collaborative learning activities and knowledge transfer. Much data was collected but it created little improved knowledge to the users. These large data sets could be used to train models using supervised or unsupervised machine learning techniques. The models, as the foundation of future services or applications, would be able to help the crews to understand and evaluate their EE performance in real time, providing opportunities of potential gains in energy saving. In a machine learning study targeting the same visited vessel, ship's performance data covering more than a year's span, combined with other data sources, were used to construct multiple machine learning models [28]. The GPS information and weather data sets were deeply explored and integrated into the models. The models take in the navigator's input on lever and other parameters from onboard sensors (such as wind speed, direction and wave height etc.) in real time. The output was the predicted fuel consumption in the near future as well as the best and worst fuel consumption values from similar voyage (considering historical wind, wave, cargo data, etc.) benchmarks [28]. Once the voyage was finished, the performance could be automatically analysed to show which period of the voyage had significant increased/decreased fuel consumption, serving as a medium for the navigators and ship engineers to share ideas and reflect upon the EE performance. With the introduction of machine learning techniques, there would be many design opportunities for the development of a real-time decision support system during the voyage as well as a post-voyage analytical system to approach the aforementioned issues.

\subsection{Shift in Knowledge Networks}

The significant business value of data-driven systems is that they provide improved operational knowledge to the ship's crew to understand the situation of fuel consumption and improve EE practices in ship-handling. For example, if an experienced navigator increases the speed at a given point in time, the system could help him to immediately foresee what would be the consequences in fuel consumption and how the rest of voyage plan would be influenced. When the voyage is completed, the engine room and bridge teams could continue collaborative learning as there is concrete and comparable information for them to review and discuss. This value is not only limited to the ship. The management group would also have better understanding of the field problems and a foundation to make more adaptive organizational decisions, such as how the optimal performance and expertise seen on one ship could 
be migrated to other ships, what resources or training opportunities the practitioners need so they can do a better job. Overall, the big data applications have huge potentials to influence the users' learning process and social relationship [29, 30].

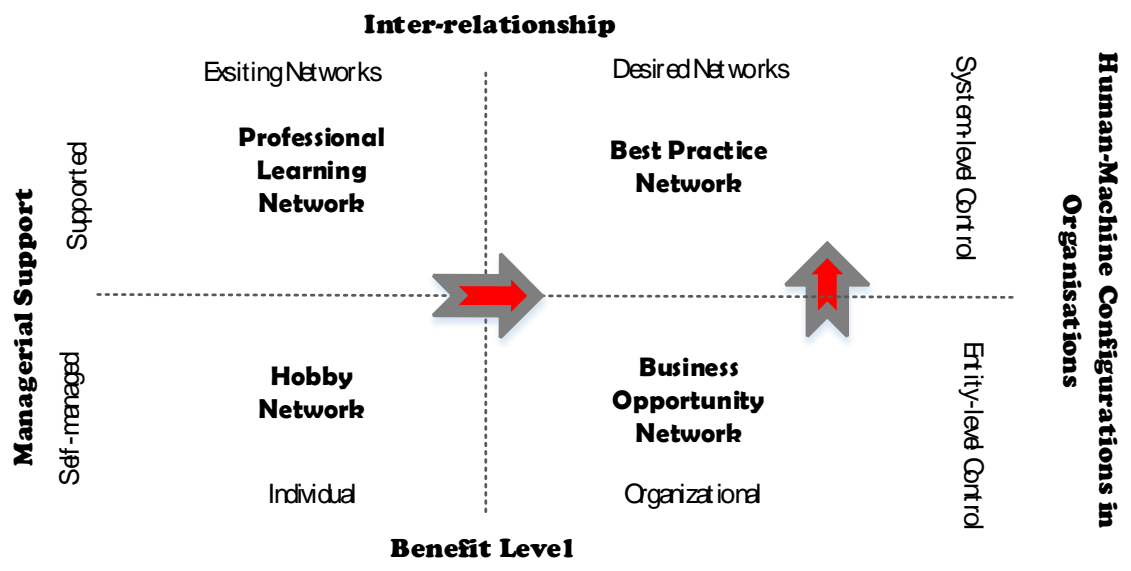

Fig. 2. The shift in knowledge management under the socio-technical impacts, adapted from the four types of knowledge-creating value network [20].

The original knowledge network framework introduces two dimensions. One dimension refers to the benefit level (i.e. individual or organizational benefits) and the other refers to the forms of networks (i.e. self-managed or supported by organizations) [20]. The emergent values in the new technology landscape suggest a significant shift of knowledge management mapped in the knowledge network framework (see Fig. 2). The current EE practice improvements are mainly based on personal interest and traditional organizational training that targets individual improvement. Therefore, the predominant knowledge networks are mainly the hobby network and professional learning networks. With the data-driven decision support/post-voyage analytical systems, the ship's crew could have concrete platforms to better understand their EE practices and evaluate the performance in both real-time and post-voyage manners. They acquire knowledge from the system and from each other. This would create a shift of knowledge networks towards business opportunity networks that are more about the creation and sharing of new knowledge for organizational benefits. Meanwhile the performance data collected from the ships would help the high-level management groups in the shipping companies to have a deeper awareness of the field situations and form a better decision-making base, so that the tacit knowledge about eco-driving on one ship could become institutionalized knowledge across the whole company. The data-driven intelligence is mostly valued not because of the data itself, but because of the close monitoring mechanism it introduces and adaptations of management it suggests. Local knowledge also can be institutionalized with proper organizational support. With the focus moved to organizational efficiency and 
institutionalization of existing knowledge, the knowledge networks are also shifted towards best practice networks.

\subsection{Towards Systems Thinking}

Rapid advances in technologies can lead to system instability and more dynamics in both system structures and interactions among system components [31]. Currently the shipping industry is heading to an ecology characterized by increasing complexity of system dynamics in which a huge amount of information would be created, integrated and shared. The relationship among agents or system components in the network would be interdependent. Systems thinking is a way of engaging the world by describing, understanding, and reconfiguring such relationships [21]. This shift in knowledge networks (impact side) must be able to address this complexity associated with the radically changing context. This is one main reason for us to abstract the horizontal dimension "benefit level" to "inter-relationship" compared to the original knowledge networks [20], so that we can highlight the impact of this shift from the system perspective. In the shipping domain, the impact transition of knowledge mobilization from an individual level to collective level manifests this development trend towards a tightly-coupled system where organizational efficiency highly depends on the extent of interactivity and connectivity. Therefore, collaborative learning, information coordination between ship and shore, engine room and deck would become more crucial than the traditional individual knowledge acquisition. The support of information sharing and collaborative learning should be an essential demand for the future design of data-driven intelligent decision-making support systems.

The agents in the networks are not only humans but also machines. Many advanced systems have been introduced to solve technical problems arising from the management of high complexity [32]. To some extent, the machines are affording more than aids but play a role as a "teammate" to coordinate information. One instance is that if the supportive tool is more functional and transparent in terms of situation assessment and performance prediction for the goals of safety (e.g. collision avoidance) and efficiency (e.g. fuel consumption), then the whole system would likely have more adaptive and improved performance. This is because the ultimate decision makers in the system, the navigators, would have better opportunities to understand the world to perform adaptively and proactively, e.g. the constantly evolving situation, consequences and meanings of system behaviours, etc. In the new technology landscape, intelligent systems and human operators are more unlikely to be two separate parts as the traditions of automation design describe - what machines do and what humans do [15]. Rather, they need to increasingly collaborate with each other to be able to amplify success and/or recover from failure, to achieve the common goal of safety and efficiency. Applying the perspective of a network of interconnected elements address the question about "what is connected" and may be more effective in coping with complexities than "who does what" [33].

Intelligent machines may already inspire humans to play the game of Go today, but they would likely have more potential if the system is situated in a highly dynamic and complex context. The shift of knowledge management in the framework of the knowledge networks and the emergent properties of human-machine collaboration in 
complex systems suggest several important hallmarks of knowledge mobilization in the new technology landscape:

1. Knowledge mobilization shall not be conceptualized as unidirectional flow from one to the other. The user can programme the machine but the machine may also create knowledge and values that can contribute to the task goal and the user's expertise. Knowledge transfer is conceptualized as a dynamic by-product of interactions among agents in the network [21]. It implies the emergence of humanmachine cooperative approach or human-machine partnership, which can significantly influence the system design. For example, if the data is associated with the user's behaviour or preferences, then automation could be shaped to afford a more customized learning approach. Machine and human are jointly controlling the domain or environment thus the desired system outcome could hardly be achieved with the absence of any agent.

2. Knowledge mobilization within the dynamic situations characterized of high temporal and spatial constraints is highly context-sensitive. This transcends the notion of knowledge transfer in the traditional human-computer interaction framework, where information is transmitted as objects (e.g. commands or displayed messages) from one to the other regardless of the situated context. Applying knowledge is about adaptation from one context to another, so a system that aims to support knowledge mobilization should never ignore the context.

3. Whether to have managerial support in the original knowledge networks [20] is essentially a question of how to manage the assets that create knowledge in a specific social environment. With rapid development in technologies, knowledge management is embodied in human-machine configurations within a certain context, thus the mobilization could be on a local or global scale. If we consider the Dynamic Knowledge Transfer Capacity Model [21] to describe the prerequisite capacities important for knowledge translation (i.e. generative capacity, disseminate capacity, absorptive capacity and adaptive capacity), then the representation associated with the human-machine configurations can be exemplified at different levels in the social-technical systems, e.g. at the departmental, organizational, industrial and social levels (see Table 1). The aim to provide the representation is never meant to address the traditional issue of "who does what", but to shed light on the possibilities for knowledge mobilization on multiple scales and suggest the importance of having human and automation coordinated [15] to form a synergy in this age of human-technology interaction.

From a systems perspective, knowledge mobilization transferring from entity or component level to a system level, from self-management to managerial support suggests that organizational efficiency is a joint effort by the practitioners, the management and the technical systems. Organisational decision-making and governmental policy-making grounded on the data is essentially a bottom-up management approach to involve the end-users in the development process of a sustainable social and technical infrastructure. With the shifts of knowledge networks, we hope to derive design and management implications of the system infrastructure contributing to knowledge mobilisation across the shipping industry as well as a safe, efficient and sustainable shipping business model. 
Table 1. Prerequisite capacities' representation associated with the human-machine configurations at various levels.

\begin{tabular}{|c|c|c|c|c|}
\hline & Department & Organisation & Industry & Society \\
\hline $\begin{array}{l}\text { Generative } \\
\text { Capacity }\end{array}$ & $\begin{array}{l}\text { Navigators monitor } \\
\text { fuel consumption in } \\
\text { real time; } \\
\text { automation uses } \\
\text { historical data to } \\
\text { describe EE } \\
\text { performance and } \\
\text { provide prediction. }\end{array}$ & $\begin{array}{l}\text { Management } \\
\text { monitor EE } \\
\text { performance for } \\
\text { the whole fleet; } \\
\text { automation } \\
\text { synthesizes EE } \\
\text { performance data } \\
\text { from each vessel. }\end{array}$ & $\begin{array}{l}\text { Classification } \\
\text { society can } \\
\text { monitor trends in } \\
\text { the shipping } \\
\text { industry; } \\
\text { automation } \\
\text { synthesizes EE } \\
\text { performance from } \\
\text { each sectors. }\end{array}$ & $\begin{array}{c}\text { IMO can } \\
\text { monitor } \\
\text { dynamics in the } \\
\text { industry; } \\
\text { automation } \\
\text { synthesizes } \\
\text { performance } \\
\text { reports. }\end{array}$ \\
\hline $\begin{array}{c}\text { Disseminative } \\
\text { Capacity }\end{array}$ & $\begin{array}{l}\text { Communicate with } \\
\text { other practitioners; } \\
\text { automation displays } \\
\text { information and } \\
\text { forwards signals to } \\
\text { system components. }\end{array}$ & $\begin{array}{c}\text { Set up } \\
\text { organisational } \\
\text { communication } \\
\text { channels to } \\
\text { understand needs; } \\
\text { automation } \\
\text { provides } \\
\text { monitoring loops. }\end{array}$ & $\begin{array}{l}\text { Set up networks to } \\
\text { discuss standards } \\
\text { for construction } \\
\text { and operation of } \\
\text { ships; automation } \\
\text { provides } \\
\text { monitoring loops. }\end{array}$ & $\begin{array}{c}\text { Facilitate } \\
\text { development of } \\
\text { social and } \\
\text { technological } \\
\text { infrastructure } \\
\text { (e.g. E-nav } \\
\text { [34]). }\end{array}$ \\
\hline $\begin{array}{l}\text { Absorptive } \\
\text { Capacity }\end{array}$ & $\begin{array}{c}\text { Apply the } \\
\text { knowledge to eco- } \\
\text { driving; automation } \\
\text { constantly evolves } \\
\text { the model. }\end{array}$ & $\begin{array}{l}\text { Locate problems } \\
\text { and tailor the } \\
\text { training } \\
\text { programmes for } \\
\text { each vessel / } \\
\text { route. }\end{array}$ & $\begin{array}{l}\text { Optimize rules and } \\
\text { regulations, } \\
\text { support } \\
\text { management; } \\
\text { automation adapts } \\
\text { to new rules. }\end{array}$ & $\begin{array}{l}\text { Adjust existing } \\
\text { regulations and } \\
\text { develop new } \\
\text { policy } \\
\text { frameworks. }\end{array}$ \\
\hline $\begin{array}{l}\text { Adaptive } \\
\text { Capacity }\end{array}$ & $\begin{array}{l}\text { Continuous } \\
\text { learning in eco- } \\
\text { driving; automation } \\
\text { adjusts speed based } \\
\text { on machine } \\
\text { learning. }\end{array}$ & $\begin{array}{l}\text { Allocate resources } \\
\text { to transfer tacit } \\
\text { knowledge to } \\
\text { institutionalized } \\
\text { knowledge. }\end{array}$ & $\begin{array}{l}\text { Create conditions } \\
\text { to motivate better } \\
\text { EE performance of } \\
\text { the whole industry. }\end{array}$ & $\begin{array}{l}\text { Monitor } \\
\text { feedback loops } \\
\text { and ensure } \\
\text { contribution to } \\
\text { sustainability of } \\
\text { the society. }\end{array}$ \\
\hline
\end{tabular}

\section{Summary}

The paper describes how the existing knowledge networks in the shipping industry could evolve in this emerging data-driven ecology. It uses challenges and barriers discovered in a case study about ship EE to address how knowledge mobilisation should address the context change and proposes a focus of knowledge networks shifting towards a collective level with data-driven managerial support. The study also discusses the characteristics associated with such knowledge mobilisation from a systems perspective and exemplifies how the prerequisite capacities important for knowledge translation could be represented on multiple levels.

Absorbing and applying knowledge is not about transferring knowledge as an object but about adaptation from one context to another. The evolution of knowledge networks and the representation of human-machine partnerships is in sharp contrast to the traditional way of learning by self-managing, institutionalised training or solely from human-generated knowledge. In the emerging data-driven ecology, intellectual 
systems have great potentials to "learn" without being explicitly programmed. More importantly, they can create new paths for the human counterpart to develop knowledge of the domain in an adaptive manner and shape the way humans understand the world. This paper provides insights on knowledge adaptation from the traditional human-machine interaction context to human-machine collaboration context and thus shapes a discussion intended to derive design and management implications of the system infrastructure contributing to a safe, efficient and sustainable shipping business model.

Acknowledgments. We gratefully acknowledge the financial support from Kungl. Vetenskaps- och Vitterhets-Samhället i Göteborg (KVVS) and Chalmers Research Fund.

\section{References}

1. Ford, M., Rise of the robots: technology and the threat of a jobless future. 2015, New York, USA: Basic Books.

2. Hyacinth, B.T., The future of leadership: rise of automation, robotics and artificial intelligence. 2017, USA: MBA Caribbean Organisation.

3. Kaczynski, T., The Unabomber Manifesto: Industrial Society and Its Future 2008, USA: WingSpan Classics.

4. Robson, J., The complexity of Go, in Proceedings of the IFIP 9th World Computer Congress on Information Processing. 1983. p. 413-417.

5. Silver, D., et al., Mastering the game of Go with deep neural networks and tree search. Nature, 2016. 529(7587): p. 484-489.

6. Rasmussen, J., Skills, rules, and knowledge; signals, signs, and symbols, and other distinctions in human performance models, in System design for human interaction. 1987, IEEE Press. p. 291-300.

7. Man, Y., et al., Gaps Between Users and Designers: A Usability Study About a TabletBased Application Used on Ship Bridges, in Advances in Human Aspects of Transportation: Proceedings of the AHFE 2017 International Conference on Human Factors in Transportation, July 17-21, 2017, The Westin Bonaventure Hotel, Los Angeles, California, USA, N.A. Stanton, Editor. 2018, Springer International Publishing: Cham. p. 213-224.

8. Viktorelius, M. and M. Lundh, The Role of Distributed Cognition in Ship Energy Optimization, in Energy Efficient Ships. 2016: London, UK.

9. PortTechnology. Watch China's Biggest Automated Terminal in Action. 2017 [cited 2018 10th February]; Available from: https://www.porttechnology.org/news/watch_chinas_ biggest_automated_terminal_in_action.

10. Man, Y., M. Lundh, and T. Porathe, Seeking harmony in shore-based unmanned ship handling - From the perspective of human factors, what is the difference we need to focus on from being onboard to onshore, in 5th International Conference on Applied Human Factors and Ergonomics and the Affiliated Conferences, N. Stanton, et al., Editors. 2014, AHFE Conference: Krakow, Poland.

11. MacKinnon, S.N., et al., Command and Control of Unmanned Vessels: Keep Shore Based Operators In-The-Loop, in NAV 2015 18th International Conference on Ships and Shipping Research. 2015: Milan, Italy. 
12. Man, Y., et al., From Desk To Field - Human Factor Issues In Remote Monitoring and Controlling of Autonomous Unmanned Vessels, in 6th International Conference on Applied Human Factors and Ergonomics (AHFE 2015) and the Affiliated Conferences, AHFE 2015. 2015: Las Vegas.

13. Hoc, J.-M., From human-machine interaction to human-machine cooperation. Ergonomics, 2000. 43(7): p. 833-843.

14. Trujillo, A.C., et al., Operator informational needs for multiple autonomous small vehicles, in 6th International Conference on Applied Human Factors and Ergonomics and the Affiliated Conferences. 2015: Las Vegas, USA.

15. Dekker, S.W.A. and D.D. Woods, MABA-MABA or Abracadabra? Progress on HumanAutomation Co-ordination. Cognition, Technology \& Work, 2002. 4(4): p. 240-244.

16. Bännstrand, M., et al., Study on the optimization of energy consumption as part of implementation of a Ship Energy Efficiency Management Plan (SEEMP). 2016, International Maritime Organisation (IMO): London, UK.

17. Johnson, H. and K. Andersson, Barriers to energy efficiency in shipping. WMU Journal of Maritime Affairs, 2016. 15(1): p. 79-96.

18. Sheridan, T.B., Human-Robot Interaction: Status and Challenges. Human Factors, 2016. 58(4): p. 525-532.

19. Röling, N., The emergence of knowledge systems thinking: A changing perception of relationships among innovation, knowledge process and configuration. Knowledge and Policy, 1992. 5(1): p. 42-64.

20. Büchel, B. and S. Raub, Building Knowledge-creating Value Networks. European Management Journal, 2002. 20(6): p. 587-596.

21. Parent, R., M. Roy, and D. St-Jacques, A systems - based dynamic knowledge transfer capacity model. Journal of Knowledge Management, 2007. 11(6): p. 81-93.

22. Lave, J., Situating learning in communities of practice. Perspectives on socially shared cognition, ed. J.L. L. Resnick, and S. Teasley. 1991, Washington, DC: APA.

23. Wenger, E., Communities of practice: Learning, meaning, and identity. 1998: Cambridge university press.

24. UNECLAC, Measures to improve energy efficiency in shipping. FACILITATION OF TRANSPORT AND TRADE IN LATIN AMERICA AND THE CARIBBEAN, 2013. 8(324).

25. Kitada, M. and A. Ölçer. A Contemporary Outlook on Human Element in Energy Efficient Seaborne Transportation. in 16th IAMU Annual General Assembly. 2015. Opatija, Croatia.

26. Viktorelius, M., The human and social dimension of energy efficient ship operation, in The International Conference on Maritime Energy Management. 2017: Malmö, Sweden.

27. Viktorelius, M., Expanding practice theory in energy research - a cultural-historical activity perspective. Energy Research and Social Science, 2017. Under reviewing. .

28. Sturm, T., Sensor data anlytics for decision support systems on ferry vessels. 2016, Kalsruhe institute of Technology; Chalmers University of Technology: Karlsruhe.

29. PwC, The human factor: Working with machines to make big decisions, in PwC's Global Data and Analytics 2016: Big Data. 2016, PwC: US.

30. Viktor Mayer-Schönberger and K. Cukier, Big Data: A Revolution That Will Transform How We Live, Work, and Think. 2013, UK: John Murray.

31. Hancock, P.A., et al., Human-Automation Interaction Research: Past, Present, and Future. Ergonomics in Design: The Quarterly of Human Factors Applications, 2013. 21(2): p. 914.

32. Hoc, J.-M., Towards a cognitive approach to human-machine cooperation in dynamic situations. International Journal of Human-Computer Studies, 2001. 54(4): p. 509-540. 
33. John, D.L., Perspectives on Automotive Automation and Autonomy. Journal of Cognitive Engineering and Decision Making, 2017. 12(1): p. 53-57.

34. IMO. E-Navigation. 2014 [cited 2017 March 6]; Available from: http://www.imo.org/ en/OurWork/safety/navigation/pages/enavigation.aspx. 